\title{
7 Building a Community Through Service Design and Responsiveness to Emotions
}

\author{
Mariluz Soto Hormazábal, Katherine Mollenhauer, \\ Satu Miettinen and Melanie Sarantou
}

\section{Introduction}

This chapter explores emerging decolonial approaches to service design in the context of a Chilean education and design community. The chapter draws on reflection-onaction (Schön, 1984) about a project that was based on the formal certification of quality, which is an official process to probe the constant improvement of educational programmes of Chilean universities. Reflections were made by the authors, who were teachers, facilitators and managers of the Master in Advanced Design (MADA) of the School of Design at the Pontificia Universidad Católica of Chile (PUC). This chapter shows how a formal and structured process, which is usually based on more topdown administrative management, can contribute to building relationships within a programme. The project, which resulted in defining a community, was implemented over a two-year period from 2015-2017.

The School of Design approached the evaluation certification process by focusing on the users of the courses; that is, the students. In other words, the comprehensive evaluation process of MADA was designed from the onset to include students in every stage of the evaluation. The purpose of the project was to strengthen collaborative practices amongst students, graduates, lecturers and managers; hence, the evaluation process sought to create a sense of community by first listening to the ideas and needs of the participants in the MADA programme, followed by careful considerations for implementing actions for improving student experiences.

MADA has had nine years of uninterrupted trajectory from 2011-2020, and has delivered more than 100 graduates. It is a programme aimed at professionals from different disciplines seeking to develop advanced design capabilities to transform communities, society and/or organisational contexts from a strategic perspective through processes of economic and/or social value creation. The students are from different fields-mainly from design, but also from engineering, architecture, journalism, arts, pedagogy and more. The teachers are mainly from design and other related fields, all of them with a master's degree as a minimum qualification. Classes are held in the evening (6:30-9:30 pm), and only some classes are conducted during the daytime, mostly on Saturday mornings. Therefore, students and teachers work during the day and attend classes after the usual working hours. Students are encouraged to complete their master's study in two years, which is why they need a certain number of credits every semester and attend classes at least three times a week. It is an intense modality 


\section{Mariluz Soto Hormazábal et al.}

for those who work and study. Training at MADA focuses on: 1) intervention projects with the objective to use solution-oriented and sustainable design and technology; and 2) systematising the process of transformation they have experienced by the creation of instrumental design-driven models that enable replicating and/or scaling of solutions in contexts of similar characteristics (Mollenhauer et al., 2020).

In the project, the key actors of the process were students, graduates, teachers, facilitators and managers who, although they had a good relationship, had not discussed each other's expectations or how, according to their role, they expected the programme to continue growing. Within the implemented project, which is the case explained here, that relationship was strengthened by listening to and fostering egalitarian dialogue to agree on what this community would be like and by considering each individual and group perspective. During the process, a selection of graduates, student representatives, facilitators and teachers from PUC were involved in a cyclical process that drew on participatory service design approaches and methods for the quality certification process.

The aim of the process was to include the student communities in the decisionmaking for implementing future strategies; hence, a practical and strategic roadmap for future programme development, marketing, implementation and evaluation was developed collaboratively. The School of Design sought to understand the needs of their student communities, avoiding the continued management of learning programmes that are based on assumptions about the needs of the communities. The process included three process cycles during which data were collected over a six-month period. After each cycle, data were collated and analysed. The second and third cycles built on the knowledge gained from the previous cycle. The process did not focus from the onset on decolonial methodologies, approaches or aims, but this chapter will review the process through a decolonial lens, with the aim of exploring to what extent the practices may have contributed to decolonial approaches in the specific context of the quality certification process at MADA.

Mapping and conceptualising decolonising approaches in tertiary education contexts in South America is possible through the lens of student movements and emerging praxis that are underpinned by pedagogies of emancipation and by autonomous and more democratic knowledge co-creation (Motta et al., 2020). In Chile, the education system promotes the educational ideal of 'inclusion, social mobility, personal fulfilment and liberation' that is underpinned by the Chilean Inclusion Law, according to Lohaus-Reyes (2019, p. 76). Further, she aptly explained how the Chilean curriculum is a result of laws and reforms that aim to establish such ideals for inclusion, but that a gap exists between its theories and praxis. The curriculum, which is expected to serve as 'connective tissue that is supposed to link diverse identities, expectations and realities', often portrays a 'language of objectives and standards, instead of worrying about its content and relevance with respect to the local context' (p. 76), thus failing to connect with the realities and knowledge systems of local communities and cultures.

In this sense, some Chilean curricula continue to reveal some colonial vestiges, with a tendency to portray power that can render locals as incapable and inferior (see Mignolo, 2006). Lohaus-Reyes (2019) has written about decolonising approaches to curriculum development in Chile, claiming that 'efforts of the teachers, students and communities who become conscious of the diversity, share and visibilise their education practices with others who are not familiar with their reality' (p. 79). From this perspective, the chapter will explore decolonising approaches in the quality certification 
process of a master's programme at a Chilean tertiary education institution. The aim will be to refrain from ways in which problems are commonly solved in the Chilean education context as previously outlined. Rather, a focus will be placed on diversity and building on various processes in educational contexts; for example, evaluation and quality assurance that can share and visibilise local knowledge.

The aim of this chapter is to view the process that emerged at MADA through decolonising approaches, which Tunstall (2013, p. 238) has described as the arrangement of 'methods, principles, and rules [that] contributes to the self-definition and selfdetermination of those formerly colonized'. Decolonising is about ongoing reflection on how to change the way that we think by re-evaluating and resituating experiences and expressions that can contribute to respectful dialogue. Such values tie in with how Lohaus-Reyes (2019, p. 7) sees the importance of decolonisation in the Chilean educational context as a means to recontextualise 'a space for dialogue where the voice of those who teach and learn can be seen and expressed'. The aforementioned authors have warned against mere exercises of theorisation; hence, caution is needed when decolonising approaches are attempted in contexts of design and innovation (Tunstall, 2013) or education (Lohaus-Reyes, 2019, p. 79).

A vast body of work exists that discusses the need for decolonising approaches in knowledge production, research, education and pedagogical contexts (see e.g. Bhambra et al., 2018; Mignolo, 2006; Smith, 1999; Walker, 2000). Unpacking the main strands of the discourse will be beyond the scope of this chapter, as it focuses on a specific case study in the Chilean context. Thus, the gap that this chapter seeks to address is how the comprehensive quality certification process in a Chilean context may have practically contributed to decolonising higher education practices in quality certification by bringing together and providing opportunities for discourse amongst the course leaders, teachers and a community of students and graduates. We explore how participatory service design may have contributed towards taking humble steps for integrating local knowledge in the evaluation process.

The evaluation process will consider the role of emotions and decision-making when applying service design and co-creation as collaborative practice that is needed when designing more inclusive evaluation processes. Decision-making in this chapter refers to collaborative practice and co-design of facilitator-service designers and the student community. Also, it is defined by the two-fold process described by Aven and Zio (2011, p. 64): '(a) how to faithfully represent and express the knowledge available to best support the decision making and (b) how to best inform the decision maker'. Emotions can be both conscious and unconscious, and they manifest as neurophysiological changes that can be brought on by responses to feelings, thoughts, moods and creativity, to name a few (Cabanac, 2002; Plutchik, 2001, p. 346). A very large number of emotions have been identified in various cultural settings, but emotions remain difficult to define (Plutchik, 2001, p. 344). Authors have identified the number of basic emotions differently, but several agree on fear, anger, sadness and joy (Soto et al., 2020, p. 91).

Ekman and Cordaro (2011, p. 364) included culture-specific feeling states, defining emotions as 'discrete, automatic responses to universally shared, culture-specific and individual-specific events'. Emotions can be considered one of the essential elements in meaningful decision-making processes (Frijda, 1988; Frijda \& Parrot, 2011; Lerner et al., 2015). In the cyclical participatory service design process, the focus is placed on the integration of body, emotion and mind of all the participants, teachers and 


\section{Mariluz Soto Hormazábal et al.}

facilitators. The connection between emotions and decision-making can become tangible during collaborative workshops and facilitation by service designers, who should foster respect and equality in their roles as facilitators by presenting information that is supported by local knowledge of the community in order to best inform decision-makers.

In the context of co-creation, service designers can promote open attitudes, listening first, and using their experience and knowledge to promote respectful interactions and communication amongst participants, resulting in personal and collective benefits. Service design which involves communities provides an appropriate framework for collaboration and dialogue with the members of a community (Miettinen et al., 2016). Participatory service design practice creates a collaborative platform where users and the various stakeholders of any community (i.e. organisation, institution, company, group, municipality, etc.) have an active and essential part to play in design processes. More importantly, service design will lead to beneficial implementation and action by the communities who engage in design. Thus, this chapter posits the following questions: How can the consideration of participants' emotions support more democratic and inclusive decision-making through service design workshops? What can be learned from this specific evaluation process in Chile to be further used and implemented in decolonising approaches?

This chapter is organised in four parts: the first presents the theoretical framework that clarifies the key concepts that underpin the arguments presented here; the second explains the research method, tools and process; the third part reveals the findings of the project; and finally, the fourth proposes a discussion on the reflections and the lessons learned during the project.

\section{Theoretical Framework}

The theoretical framework is built around the concepts of service design and decolonising approaches to the role of emotions in facilitating democratic decision-making in co-creative processes with communities. The role of co-creation in shaping connections and interaction within communities through dialogue and interaction will be considered.

\section{Decolonising Design and Service Design}

The terms design and development carry strong connotations and associations with the West or the First World (Ghose, 1989, p. 39). Design is closely linked to Western technology, imperialism and colonialism (Ghose, 1989, p. 32; Tunstall, 2013, p. 234). The clarification of the purpose of designers in any given context is necessary, as well as questioning their roles and their contributions to communities (Tunstall, 2013). By drawing on the practical approach suggested by Khandwala (2019), practical steps for decolonising design can be outlined. She asked how designers can adjust their thinking to critically evaluate their design practices. First, designers have to acknowledge that design, as such, does not disrupt practices as it is often closely connected to Western ideologies that are built on a system of privilege, the extraction of resources from the colonised and capitalist ways of doing (2019). As practical steps, decolonising design can be framed by the following critical views described by Khandwala (2019): 
- Diligence and ongoing critical reflection are needed for implementing decolonising practices.

- False divides and distinctions amongst art, craft and design should be omitted (in addition, see Tunstall, 2013) to acknowledge all cultural forms of creation and making.

- Question the familiar, disrupt established orders and question how solutions may be experienced by others.

- Question your role as designer in a process or project, acknowledge when some roles are not yours to take and step aside (also if not-for-profit work is involved) to create spaces for locally practicing designers to gain a foothold in creative communities to sustain their livelihoods.

- Continue self-education and curiosity, and acknowledge that design is not a neutral practice.

Participatory and socially engaged service design aims to generate social transformations (Miettinen \& Valtonen, 2013); hence, it draws on the abilities and decisions of individuals and groups who can, through their behavioural perspectives and their specific and subtle actions, influence and instigate such transformations (Thaler \& Sunstein, 2009). Service design is a holistic research and application field that enables improved services and experiences (Moritz, 2005). Moreover, service design endows professionals with specific communication and empathic skills (Miettinen et al., 2014) which can also be applied to learning (Kuure et al., 2014). According to Manzini (2009, p. 45), services are 'interactions between people who cooperate to produce a commonly recognized value'. As a result, the services created with and by communities can support collaborative interaction, as services that are created and implemented by communities are underpinned by user and stakeholder integration.

Service design is facilitated through the visualisation of processes, iterative actions and reflections on the processes, which are underpinned by possibilities for anticipating certain situations (Miettinen \& Sarantou, 2019). Service designers should be aware of and consider the possible differences in people's lives by asking 'whose stories are being privileged and whose stories are being marginalised in any representations of the Other' (Wilson, 2001, p. 217). They need a willingness to abandon a privileged role, considering the user as part of a network of relationships and not simply a means to predestined and designed outcomes (Schultz et al., 2018). Therefore, this approach is oriented towards the critical perspectives that promote decolonising approaches, as emphasised by Khandwala (2019) and Tunstall (2013). Service designers, in their roles as facilitators, should work towards the undoing of dominant structures and lower their own expectations, visions and purposes in terms of project outcomes that would be acceptable in their own contexts. Such approaches, which enable communities to design by themselves, foster appreciation for plurality and diversity as the basis of design processes. Despite the perpetuation of established power structures, by adopting decolonising approaches, facilitators can effectively analyse and then question these structures. When facilitators of service design workshops include respectful practices such as listening and valorising the heterogeneous experiences of each member of the community whereby the position of everyone is viewed as equal, horizontal interactions amongst the community can potentially be strengthened.

In service design, the role of the facilitator is essential and not limited to workshop environments, but also includes being a project coordinator (Miettinen \& Valtonen, 
2013). Service designers have to change or adapt their mindset and critically consider the frameworks that guide their actions. The performance of the facilitator, besides applying methods and techniques, can be evaluated according to the extent to which collaboration and commitment of the participants are maintained (Hogan, 2007). Developing communication and practical skills that are sensitive to the emotions which are exteriorised by the expressions and behaviours of people and that sustain a continual flow of dialogue are necessary. The facilitator can encourage collective thought, which is 'people thinking together' according to Bohm (2013, p. 29). Emphatic approaches and respectful and inclusive perspectives, as well as the sensemaking abilities of facilitators, can enhance connections amongst people. The mentioned approaches often come about through 'persistent unlearning and relearning [how] to see the world' (Schultz et al., 2018, p. 94).

Service designers are facilitators of processes; thus, they guide processes of collective participation and draw on associations of concepts that are underpinned by complexity and diversity (Schultz et al., 2018). Within dynamic contexts, it is possible to promote the emergence of various languages, whether they are spoken, visual or alternatively expressed. The experiences service designers draw on are continuously informed by interaction itself, which impacts co-created results and outcomes. Service design processes may combine a variety of emotional and decision-making aspects by constant dialogue that may come about through prototyping actions and co-creation activities.

\section{Emotions and Decision-Making}

Flexibility to continuously adapt perceptions can enhance the abilities of service designers to gauge their decision-making in facilitation processes according to their intuition and emotions (Lerner et al., 2015). Therefore, depending on conditions in their environments of operation and interaction, emotions arise that can influence and guide decisions. In this chapter, emotions will be considered according to their role in decision- and meaning-making (Lerner et al., 2015). Emotions influence people's responses according to the inspiration that emerges from life experiences (Mattelmäki et al., 2014), and they can drive people's interactions and their emotional responses (Mikkonen, 2017). Possible responses to a variety of information (George \& Dane, 2016) also influence emotions. Emotions are constantly fuelled by people's experiences, which have an impact on the present and an influence on future decisions (Soto, 2018). Experiences are influenced by interactions with people, objects and the environment. Intuitions are driven by stimuli such as temperature, light, colour, smell and other sensations (Norman, 2004). Intuition and visceral sensing can impact participants' emotions in co-creative processes because each will react according to the intuitive stimuli that they receive during the process from their immediate environment and from their previous experiences. These factors play a role in their judgements about the situation they are experiencing.

Emotions in service design workshops are related to emotions that arise in the interaction between people and between people and their environment, which is different from emotions related to products which place the emphasis on the interaction between people and objects (Desmet, 2002). The complexity of emotions in an interactive environment is influenced by factors related to the perceptions and previous experiences of participants in service design processes. When service design is based on a participatory perspective, the emotions of the participants, users, stakeholders and service designers become relevant. Emotions in co-creation contexts present many challenges for service designers in their role as facilitators. The emotions of 
participants need to be recognised and acknowledged during workshops, while service designers and facilitators need to come to terms with their own emotions, such as satisfaction or frustration, which relate to positive or negative results. In addition, their emotions can fluctuate when promoting and guiding dialogue (Soto et al., 2020).

Emotional aspects and their integration into decision-making are influenced by pluralities of vision and the knowledge that participants themselves produce during a process (Schultz et al., 2018). In the context of this chapter, such integration finds an explicit application in the perception, understanding and defining of community by its members, whether they are current or former students, teachers, facilitators or course leaders. The construction of a shared vision in a community context provides members with new means and motivation to take and enact their decisions. Service designers and facilitators can play a key role in encouraging and perhaps even challenging participants to manage their choices based on their emotions, but keeping in mind that flexibility is needed in community contexts as changes may occur in the relationships, common visions and shared perspectives of the community, this impacting the anticipated results.

\section{Co-Creation}

Co-creation is a broad term that can have connotations that range from concrete to abstract depending on the context. It refers to any collective creation activity (Sanders \& Stappers, 2008) and is understood as a collective creative process with several influencing factors that could determine the perception and quality of the experience. One of the essential elements of co-creation is that people participate in a shared space by learning from their personal experiences while influencing their collective experience (Prahalad \& Ramaswamy, 2004). As a practice with a specific purpose, co-creation requires a pre-design that guides actions for reaching a goal. Therefore, the production of knowledge comes about in a shared space and is achieved by the participants of the co-creation process themselves (Schultz et al., 2018). Designers can facilitate and guide the process, and in participatory service design, community members are involved in various roles of the process, depending on the levels of responsibility they can and want to take on (see Chapter 10 of this book).

The skills required to guide co-creative processes are closely related to the ability to establish creative relationships. Co-creation processes that are guided by decolonising design approaches encourage open attitudes and capabilities for articulating interests and learning processes (Khandwala, 2019), which come about through interactions with others. Although there may be restrictions on the position or role that people fulfil in a certain structure (Hoffman et al., 2015), co-creation can mitigate dominant structures and constraints, especially if the emotional perspectives of communities are respected. Such emotional components in decision-making, combined with decolonising practices, can impact personal and collective perceptions of co-creative communities.

\section{Dialogue, Interaction, Community}

Dialogue is an interaction that can come about between people as the 'flow of meaning' can establish common understandings (Bohm, 2013, p. 7). Attitudes of flexibility and willingness to create agreeable outcomes can enable the integration of personal interests to identify common goals. Some emotions can fuel trust or mistrust that can be experienced by participants during various interactions; hence, emotions 
can enable the strengthening of relationships or fuel relationship breakdowns. In interactions between people, the expression and communication of emotions can contribute to effective problem-solving by their clarifying communication (Lerner et al., 2015). Clear communication of emotions enables diverse perspectives and interactions within a community.

The experiences of communities should be understood as local knowledge that should be invested into co-creation which acts on behalf of the community. To improve this understanding, it is necessary to systematically and collaboratively work directly with the communities (Meroni, 2008), which requires changing the focus from the individual to the network of relationships of a community (Miettinen et al., 2016). Understanding the context in which the community operates enables scenarios to be identified as well as the people who should be involved in co-creating a product or service (Cantù et al., 2012); hence, greater precision in defining possible relationships and interactions is possible. Design is not a neutral practice, but it can be considered a tool for social integration and for the promotion of co-creation in marginalised environments (Soto \& Kaplún, 2019), with the potential to enable social cohesion relevant to each project. In the case of public services, citizens are also a community in which user/citizens establish a system of interactions through which they define their relationship and experience (Mollenhauer \& Soto, 2019).

Therefore, users understood as a community of people establish a set of actions that enable them to interact with other members (Tolosa, 2013). In such systems of interaction, their roles, relationships and sense of community are created within a given environment.

The daily interactions of people leave visible and invisible marks and traces in people's lives; behaviours and habits determine the form of interaction and relationships that people establish with others (Tolosa, 2013). In intensive work processes, a relationship of trust, or mistrust, is generated amongst participants, which is determined by a specific activity or moment (Judice, 2014). Therefore, the relationships within a community depend on the intensity of the interactions and the bonds that can be generated as a result of the respectful dialogue and perceptions that come from belonging to the community. The appreciation and respect for the experience of each member of the community is vital to avoid the hegemony and domination of some members of the community (Tunstall, 2013) and to promote equality in their interactions and relationships. Thus, encouraging horizontal and respectful interactions and the awareness of emotional plurality of participants in the co-creative process can give facilitators a holistic, inclusive and empathic approach to the community (see Chapter 10 of this book).

Community as a visible and invisible network creates, modifies, strengthens, eliminates and resignifies its relationships according to interactions and experiences. Interactions within a community are constantly changing according to the particularities that influence perceptions and experiences (Soto, 2018). The creation of a community includes a negotiation amongst its members to define various personal, social, economic and political aspects (Kuure, 2017) defining other people. One of the benefits of design with a community emphasis is the ability and intention to understand people's social behaviours and needs (Meroni, 2008). Designing with the community encourages listening respectfully and grasping the horizontal connections amongst users in a system of relationships, behaviours, expectations, visions and emotions that present in different intensities, ranging from abundantly rich to deficient (Figure 7.1). 


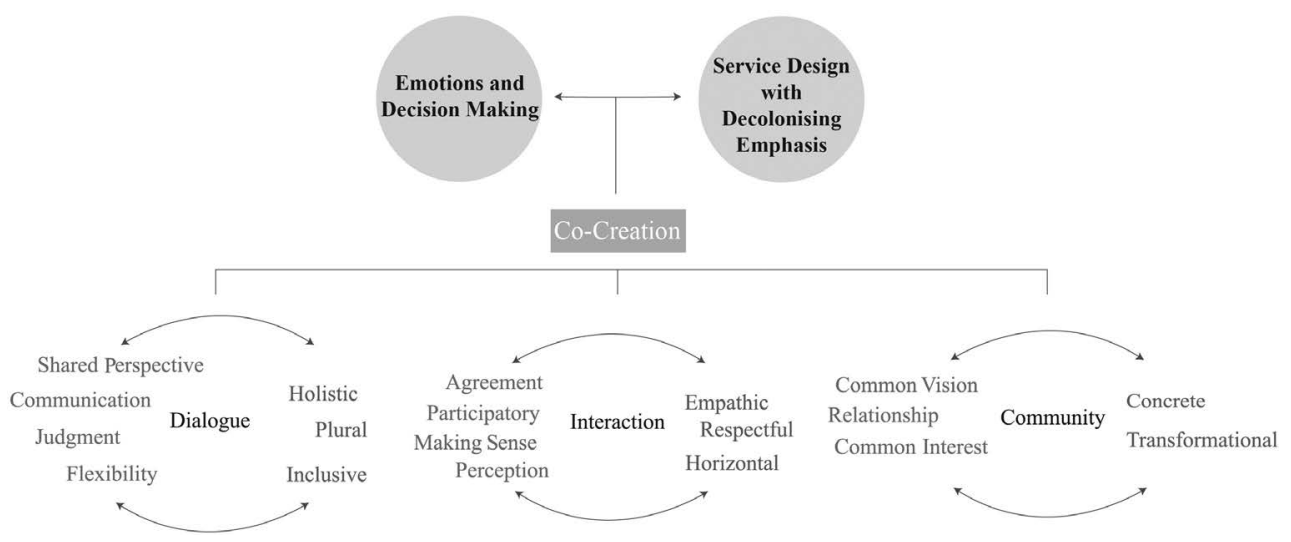

Figure 7.1 Visualisation of the concepts of the theoretical framework.

\section{Research Methods}

The data described in this chapter were collected in a case study, the MADA programme, over a six-month period from 2016-2017. The research process included three cycles during which data were collected and analysed for the development of the next cycle, but the data were also disseminated in a next cycle for the benefit and ongoing development of the community. The three cycles (Figure 7.2) consisted of three workshops that drew on a variety of research methods. Participatory service design was used as an overarching approach to strengthen participation and a sense of community.

The goal of this case study was to explore how the MADA community was strengthened through a participatory service design process that included participatory workshops, meetings and surveys (Table 7.1).

In the workshop, the participation of students, graduates, facilitators, teachers and course leaders was essential to understanding the concerns, perceptions and expectations about their learning, teaching and facilitation processes. The project followed a cyclical but flexible structure (Figure 7.2) to take into account the needs of the MADA community, possible scenarios and the role of carefully listening to the community's desires. The emotional component to decision-making was based on open communication about the process and defining activities that made sense to participants and would provide valuable experiences to the community.

Six sets of data were collected during three participatory workshops (Table 7.1), which brought together a total of 120 participants; for those workshops, different tools were developed to collect the data, described in what follows.

1. Would scenarios: The participants were organised into five groups of graduates and three teams of students. Each team identified the aspects from the programme that 'they would not like', those 'they would like' and 'how they would materialise their ideas'.

2. 3Cs matrix: The participants worked on the definition of the identity of the programme through the 3Cs, from the Spanish words cabeza (head), corazón (heart) and cuerpo (body). 


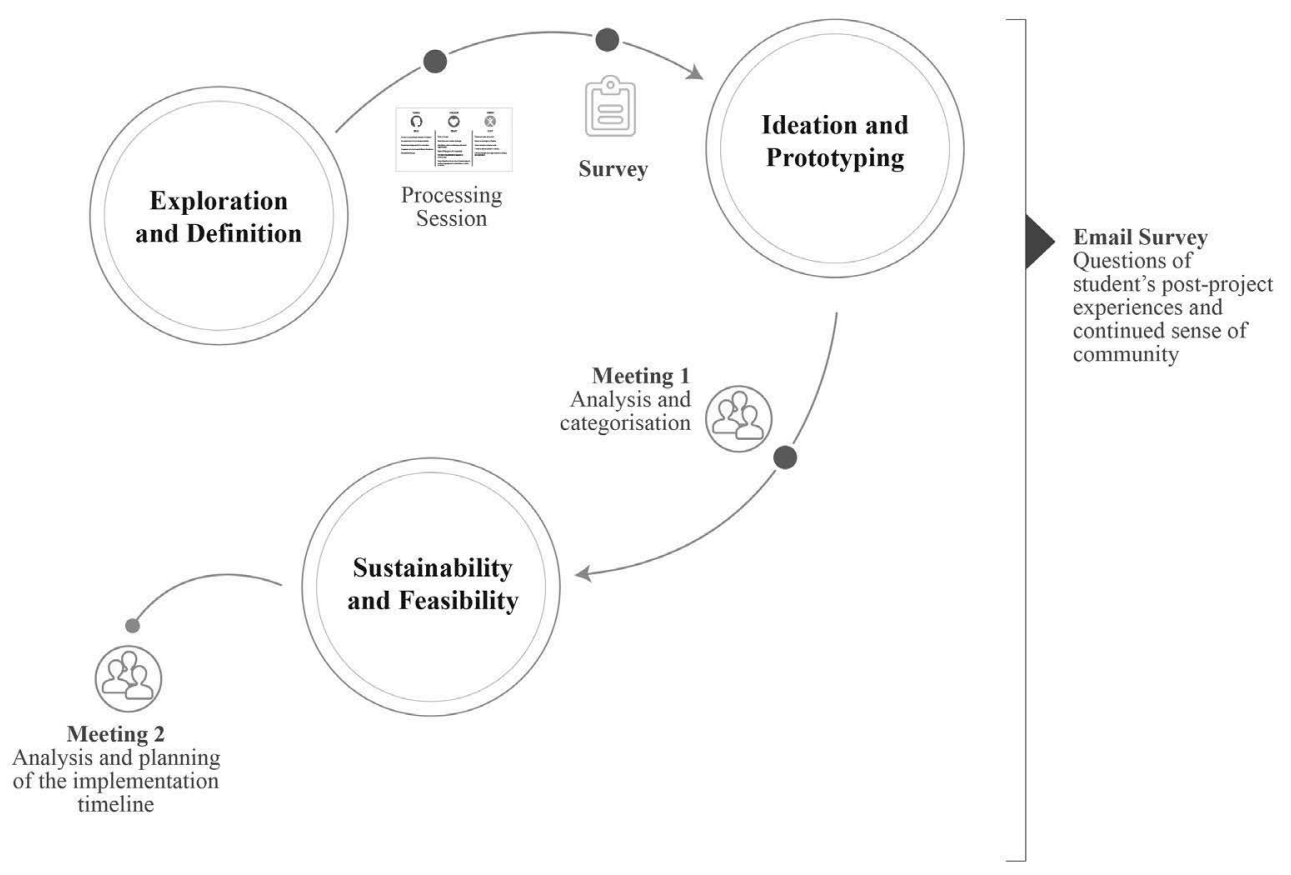

Figure 7.2 The cyclical research design process of the project.

3. Qualitative surveys that included questions: What is MADA? What do you feel about being students/graduates of MADA? What are the rituals of MADA?

4. Anecdotal data: Using the questions 'What?', 'Why?' and 'How?' to analyse the ideas, and as a way to specify and evaluate the proposals.

5. Strategic roadmap: A step-by-step plan indicating how to implement the project, including the perspectives of traceability and sustainability. This tool was applied to each proposal to identify strengths and opportunities and those that remained unaddressed.

6. Email surveys: Questions about the student's post-project experiences and continued sense of community.

The questionnaire resulted in 27 responses that identified possible actions for improvement in three specific areas: technology, infrastructure (e.g. lighting and air conditioning in the facilities, access to equipment) and aspects for improving learning experiences. The third method was to conduct two meetings with students and graduate representatives to analyse and categorise the data. The qualitative analysis of the data followed the strategy of categorisation and thematic analysis to converge the data with possible actions (Simons, 2009) from the first research cycle to the last. The analysis included the 3Cs matrix (Figure 7.3) mentioned previously. According to Tolosa (2008), the 3Cs are a way to understand people from their mental representations, emotions and behaviours. In this case, we used the matrix as a tool to visualise the three aspects related to people in a comprehensive way, specifying their 
Table 7.1 Summary of research methods

\begin{tabular}{|c|c|c|c|c|c|c|}
\hline \multirow[t]{2}{*}{$\begin{array}{l}\text { Key methods: } \\
\text { workshop, } \\
\text { focus group } \\
\text { discussion } \\
\text { and survey }\end{array}$} & \multicolumn{3}{|l|}{$\begin{array}{l}\text { Three participatory } \\
\text { workshops } \\
\text { (over a six-month } \\
\text { period) }\end{array}$} & \multirow[t]{2}{*}{$\begin{array}{l}\text { Survey } \\
\text { (10-15 minutes } \\
\text { to complete, } \\
\text { four open- } \\
\text { ended } \\
\text { questions) }\end{array}$} & \multirow[t]{2}{*}{$\begin{array}{l}\text { Two meetings, following } \\
\text { the structure of focus } \\
\text { group discussions } \\
\text { (collecting anecdotal } \\
\text { data and notes) }\end{array}$} & \multirow[t]{2}{*}{$\begin{array}{l}\text { Email survey } \\
\text { (5-10 minutes } \\
\text { to complete, } \\
\text { two open- } \\
\text { ended } \\
\text { questions) }\end{array}$} \\
\hline & $\begin{array}{l}\text { WS } 1 \text { Exploration and } \\
\text { definitions }\end{array}$ & $\begin{array}{l}\text { WS } 2 \text { Ideation and } \\
\text { prototyping }\end{array}$ & $\begin{array}{l}\text { WS } 3 \\
\text { Sustainability } \\
\text { and feasibility }\end{array}$ & & & \\
\hline Participants & 120 & & & 27 & 5 & 11 \\
\hline & $\begin{array}{l}\text { Students, graduates, } \\
\text { teachers }\end{array}$ & & & $\begin{array}{l}\text { Students, } \\
\text { graduates }\end{array}$ & $\begin{array}{l}\text { Representatives } \\
\text { of students } \\
\text { and graduates, } \\
\text { management team }\end{array}$ & $\begin{array}{l}\text { Students, } \\
\text { graduates, } \\
\text { facilitators, } \\
\text { teachers }\end{array}$ \\
\hline Objectives & $\begin{array}{l}\text { Identify the participants' } \\
\text { perception of the } \\
\text { master programme } \\
\text { performance }\end{array}$ & $\begin{array}{l}\text { Exploration of ideas } \\
\text { and co-creation } \\
\text { of the dreamed } \\
\text { community. } \\
\text { Definition of the } \\
\text { main characteristics }\end{array}$ & $\begin{array}{l}\text { Critical analysis } \\
\text { of ideas and } \\
\text { assessment of } \\
\text { feasibility }\end{array}$ & $\begin{array}{l}\text { Identify } \\
\text { actions to be } \\
\text { improved }\end{array}$ & $\begin{array}{l}\text { Review, analysis and } \\
\text { categorisation of the } \\
\text { results to be worked } \\
\text { on in the participatory } \\
\text { workshops }\end{array}$ & $\begin{array}{l}\text { Follow-up } \\
\text { with student } \\
\text { community } \\
\text { on project } \\
\text { experiences }\end{array}$ \\
\hline $\begin{array}{l}\text { Methods } \\
\text { for data } \\
\text { collection }\end{array}$ & $\begin{array}{l}\text { Would scenarios, 3Cs } \\
\text { matrix, note taking, } \\
\text { survey }\end{array}$ & $\begin{array}{l}\text { Free methods, selected } \\
\text { by the participants, } \\
\text { use of creative tools } \\
\text { and materials }\end{array}$ & $\begin{array}{l}\text { What, Why } \\
\text { and How } \\
\text { questions, } \\
\text { and business } \\
\text { model canvas }\end{array}$ & Survey data & $\begin{array}{l}\text { Anecdotal data, note } \\
\text { taking }\end{array}$ & Anecdotal data \\
\hline Time frame & 2015 & 2016 & 2017 & 2016 & 2016-2017 & 2020 \\
\hline
\end{tabular}




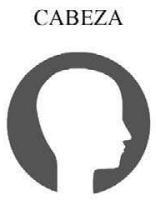

HEAD

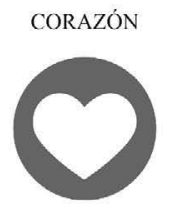

HEART

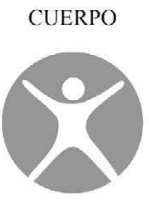

BODY
Access to professional networks.

An experience to boost entrepreneurship.

Expansion of knowledge applied to innovation.

Multicultural and interdisciplinarity integration.

Specialised training
Pride to be part of/belonging to a community.

Motivation and ongoing challenge.

Satisfaction with professional improvement.

Feeling an integral transformation.

Frustration from the use of terminologies in foreign languages.

Confusion from and dissatisfaction with receiving paternalistic treatment (similar to school).
'Post-it' notes are overrated and overused.

A large number of terminologies are English.

Excessive teamwork is difficult to accomplish due to the majority of students having a job in addition to their studies.

Study work is more in line with college than graduate study.

New knowledge encourages interest in the sharing of experiences.

Figure 7.3 3Cs matrix with the summarised experiences of the participants.

rational, emotional and behavioural characteristics. The matrix was applied to visualise the participants' perception of the postgraduate programme, defining the features of the programme in the three areas and at the same time reflecting on the implicit identity of the programme.

The three different methods for data collection were based on their suitability for the participatory design process in which the participants could, based on their experiences, define the next steps in the research cycles. These methods could be used by any project in which different visions need amalgamation as the process starts with an evaluation of what the participants and the community itself have in common and what they envisage to further develop through prototyping. The interaction in the workshops linked the participants from the first moment by creating the first steps for building a sense of community. One of the first exercises was the identification of the opportunities and limitations of the programme through an analysis of its strengths and weaknesses.

The 3Cs matrix lists the concrete, emotional and behavioural aspects of the participants' experiences. The first column shows the responses of participants related to access to new knowledge and skills, which reflects the decision to carry out a postgraduate study. The second column, mostly illustrating positive emotions, differs from the third column, which illustrates mainly negative emotions which create a gap between what is experienced and the awareness of the emotions experienced. In the heart column, most of the recorded responses involve personal significance both in individuals' perceptions and in their relationships generated with peers. However, the body column shows those aspects of the programme that do not meet expectations or in which weaknesses are detected. Therefore, in the head and heart columns, the answers are linked to an invisible or abstract aspect related to the professional and personal benefit that participants experience in the postgraduate study, as opposed to those in the body 
column. It is possible to observe that the answers refer mainly to the visible and concrete aspects that correspond to the dynamics and structure of the program.

In the second workshop, the prototyping stage, participants built the desired community with five proposals at the end, which reflected the participants' opinions of the activity. The five proposals are different from each other, but in all cases, they consider actions to be carried out virtually and in person. The virtual activities were divided into three orders: the first focused on increasing access to content, the second on advancing a virtual network and the third on enhancing the professional positioning of students and graduates. On the other hand, the face-to-face actions are shown in three of the proposals, which refer to the increase in content development activities and an infrastructure that enables compliance with the requirements that participants identified as essential for the success of MADA and their postgraduate studies.

The proposals received in one of the participatory workshops were reviewed in the first analysis and categorisation meeting. The meeting participants identified three categories: linking, learning and dissemination. First, linking includes the solutions related to the opportunities for links amongst community members and for actions that strengthen the community and improve the experience. Second, learning involves the answers obtained related to access to more meaningful content, increased support for the process (i.e. the graduation project) and access to more tools. Third, dissemination refers to the promotion of the activities and achievements of students and graduates and the possible activities and incentives of other institutions to which they may have access. All the ideas that emerged in the ideation and prototyping workshop were sorted into these three defined categories (Figure 7.4). The intersection of the three categories shows the actions that were developed during the realisation of the project, which fulfilled the possibilities of the programme for its achievement in the short and medium term.

As the title of Tolosa's (2009) article states, to communicate is to create communities. Therefore, the communicational and emotional aspects of the project were fundamental to the evaluation process for the MADA programme. One of the first actions to define the community was to start talking as a community. To support the first action according to the 3 Cs matrix outcome, it was essential to create a storyline or narrative of the programme with flexible characteristics to keep improving it for the purpose of communicating the emotions regarding the community. The purpose of this story was to integrate the expectations of students and graduates to strengthen the bond amongst them and create an explicit ground for communication decisions. The research was finalised in 2020 with post-project email surveys that focused on enquiring how the community experiences were continued and the results and impact the evaluation process had. A total of 11 respondents (students, graduates, teachers and managers) participated in the email survey.

Due to the cyclical research design of the project, the methods for data collection were selected because of their practical value and ability to deliver analysable and reliable data in a short time span. The rigorous methodology relied on methods that were able to deliver sufficient data that were collected through a focused approach. For example, graphic tools were employed and surveys consisted of a small number of key questions. A limitation of the selected approach was that the final email survey was completed long after the project ended. At least three respondents commented on 
- Welcome kit for new students

- Vitamin MADA: A set of useful tools

\section{Learning}

- Blog

- Complementary activities

- Publication of research

- Continuing education and

lifelong learning

- Coaching for the successful

and projects of graduates

- Promote work opportunities

delivery of final projects

- Welcome activity for graduates

(1)

- MADA House

\section{Dissemination}

- Offering more activities to stimulate

engagement by graduate and students

- Participation in workshops by MADA

community

- Participation in workshops offered by

other institutions

- Incentives for students to use existing

infrastucture (e.g. the FabLab equipment)

\section{Actions Developed During the Project:}

- Organising annual meetings

- Boosting the integration of students and graduates in

projects carried out by the postgraduate programm

- Generating new content of students and graduates

through new web site functions

- Making quotas available for graduates to participate in

international workshops offered by the programme

- Organising complementary activities such as talks and

seminars organised by the programme

- Expanding the networks of the programme and enable students to collaboate with partner organisations to create shared benefits for all participants and organisations

- Delivering students' services for strengthening the scope

and reach of the programme

- Supporting students' entrepreneurial and businesses activities through disseminating their achievements

Figure 7.4 Visualisation of the results during the community prototyping process. 
having difficulty remembering some details about the project. Yet, the responses of the participants clearly illustrated the impact the community-focused approach had on building a lasting sense of community as it was commented on enthusiastically three years after the project ended.

\section{Findings and Discussion}

The analysed data from the email survey were organised into three subthemes: the first discussed the role of the facilitator in service design, the second connected emotions with decolonising practices in service design and the third focused on community creation.

\section{Role of the Facilitator and Service Design}

In the role of facilitator, service designers have to be open to constant learning. Taking on a facilitator role as a designer requires a more neutral and close position with the communities that are central to the design processes, which enables proactive participation and commitment to the tasks at hand, guided by the community vision. At MADA, the user perspective meant the integration of the views of the student community. One facilitator explained this:

Bringing the user perspective into designing for services encourages the students to think about how power is used and distributed in the design process. At MADA, service design course students were encouraged to rethink the way services are designed and delivered and enable inclusion and participation of wider stakeholder groups. I see that getting students involved in this kind of critical thinking and reframing of things promotes openness and re-evaluation of learning practices. The process nature of service design encourages students to go very fast from a problem into the solution space.

Service designers strengthen their practice when they can integrate community experiences as a fundamental value in projects, specifically with the development of a sensitivity to emotions that enables connections to people through dialogue. Dialogue is one of the conditions that facilitators have to trigger, but it also depends on three key elements-process transparency, the co-creation process and horizontal logic-with the purpose of building a collaborative environment. One respondent stated: 'The emotional experience is based on dialogue, the presentation of ideas and taking collective decisions'. According to the responses, the dialogue, the sense-making and the service design methods can foster the conditions for an egalitarian and meaningful experience through the sense of belonging and the feeling that one is heard. One respondent remarked,

Two essential instances, the first of them was the creation of this community, and the way in which the needs were raised from the community itself (collaborative work and co-creation), and the second of these was the continuity that was established, allowing traceability in the development of activities and achievements of these. 
Therefore, the role of the facilitator is to flow with the participants, identify blockages and dissolve them, strengthen common spaces of creation, make agreements visible and project them in accordance with the initial purposes of the workshop.

The atmosphere and feelings that are transported in interventions, with facilitators willing to provide space for the participants, are important, as a respondent reflected: 'I think the most valuable thing was creating community gatherings in a more informal mode, where the managers stand a little "aside" and, therefore, support a more friendly and less structured environment avoiding seeing workshops as another extra activity'. Facilitators can foster the emotional conditions to build a safe and comfortable place to create, as one respondent highlighted: 'I especially value the possibility of participating, the collaborative atmosphere, the openness to different views and sensibilities, and the balance between a speculative and action-oriented exercise'. The relationship between experience and results was emphasised by another respondent who stated that 'the emotional experience is very positive, since collaborative work methodologies are applied'. The same interviewee stressed dialogue as an essential condition to transform experience into achievement.

In addition, service designers can bring their methodological strengths to the communities when asked to do so. Participants appreciated methodological rigour and guidance, as one participant stated: 'From the survey of needs, through design to implementation, throughout the process, the focus was on co-creation, participation and methodological rigour on the part of the team that led the project and it showed'. Another respondent commented on the driving value of quality: 'Continuous quality improvement as the engine of the process'.

The workshops were valued, as the perspectives on community experiences and application of existing knowledge resulted in students feeling involved in the process. One respondent noted that they made sense of the process 'through the use of the same methodology that we learn during the programme; listen to our concerns and make us participate in the entire process'. Also, one participant noted: 'We had an active role in this process, where methods and tools were used to gather information, just as we worked in our training process as students'. The transfer of knowledge through methodological approaches, as well as the application of methods that were known to the students, thus integrating their local knowledge, was evident in the collaborations between students and facilitators in this case study. At the same time, it is important to reflect on the need for some students to expand local knowledge to the level where local practices are described in local languages, so that those terms can be adopted and used (see Figure 7.3).

\section{Emotional and Decolonial Approaches in Service Design Practice}

The emotional experiences during and long after the evaluation process contributed to the fostering of individual and community identities, which were driven by emotions and a sense of belonging. Respondents used phrases such as 'feeling part of', 'reaffirm ties with my colleagues and teachers' and 'there is a "MADA profile" that I am proud to belong to'. Emotions that were driving interest and continued participation in the community long after the evaluation process ended were described as follows: 'The emotional experience is defined as rewarding and generating identity', and 'trust and satisfaction for contributing to a process of defining a community'. Additional 
comments from respondents included: 'Joy for the interest and participation of students, graduates and teachers', while another remarked: 'feeling of co-responsibility and enthusiasm'. Other positive responses about the emotions experienced during the process were: 'I was excited because everyone participated with interest and commitment, they felt comfortable,' 'in the end, I was satisfied' and 'it excites!'

However, facilitators have to retain sensitivity for a variety of emotions, which are sometimes less than ideal, including frustration, irritability or sadness, that can evolve and even erupt during working processes with communities. One respondent explained: 'Different emotions emerge at different times: sense of belonging, joy, associated with participation and companionship; frustration-sadness, associated with the lack in some cases of a critical gaze; satisfaction-optimism-joy, for future possibilities and the will to improve'. However, some participants' responses indicated that there was a need for more critical reflections during the implementation of the process cycles. Hence, the cyclical process could have benefited from more opportunities for reflection and feedback from the student community. Yet, our focus on sensitivity may have resulted in valued opinions being shared in the process, as one respondent mentioned: 'My opinion is important, I feel heard' and 'This is all worth something. I'm participating in something important'. One of the facilitators in MADA summarised the importance of the awareness of emotions in service design workshops:

Being sensitive to emotions throughout service design workshops may generate balanced workshop dynamics that enable more equal and inclusive participation of all workshop participants. Making sure that everyone is included in the discussion, enables various ways of self-expression through visual participation, enacting and so on.

The main contributions of this chapter are related to developing very practical ways in which participatory service design processes and practices can be decolonised by drawing on emotions as a means to such an end. As the preceding respondent commented, the value of inclusive and equal participation should not be underestimated, and emotions are the means that can achieve such ends as inclusive and equal participation. Emotions are valuable to facilitator/service designers, as well as other members of the community, in gauging the inner feelings and mental states of participants.

\section{Creating Community Within a Community}

The nature of community cannot be pinned down or easily defined by boundaries as it continues to reshape and reinvent itself. Community is not a concept; it is an organic and flexible flow of people that adapts to various factors and influences. One of these factors is the people who constitute communities with their emotions, reactions and silences, while other factors include the environment, interactions and the particularities of the situation. One respondent stated: 'The most valuable thing was to identify what defined us as a community and make it a conscious process by further strengthening ties and creating new ones'. Another respondent's view was: 'From the outset, the community building process was based on a strong commitment to coordinating the participation of the entire ecosystem that would be impacted by 
the initiative'. Valuing plurality and diversity when defining the community enables connections with new perspectives and therefore potentially encourages innovation. A community that values heterogeneity decreases the probability of exercising hegemony by distributing power amongst all its members by distinguishing the presence of each one as a contribution to the general purpose of the community. The value of creating the community from the community itself lies in considering people or users as co-creators of their community. This perspective diminishes colonising design practices that aim to install a predesigned vision that undermines the voice of the members of the community.

Creating communities hinges strongly on identity processes. One respondent commented on the value of community in identity processes:

The generation of a sense of belonging through welcoming ceremonies, having representatives of the students, the network of graduates, the incorporation of alumni into teaching has allowed us to strengthen the identity and cohesion of the programme and increase the complicity between teachers and students.

Identity processes not only contribute to a sense of belonging, but also to the characteristics that differentiate various communities, as another respondent said: 'I can say that we have a super particular character and identity that differentiates us from other student communities'. Emphasis should be placed on the processes that are promoted through dialogue and expression, as they can serve as ways to ensure 'continuity in the community' as one respondent reported.

Understanding that the interests of users are not necessarily the same interests of the institution is essential. By listening to the community first, it is possible to identify their various concerns and interests, and then, if possible, connect these with the interests of an institution. However, co-creative processes need to focus on negotiating and finding solutions to the needs of communities if it is not possible to connect these with the interests of organisations. In these cases, organisations need to consider how to compassionately and proactively engage in dialogue for defining and implementing local actions that can address the needs of communities. One respondent reflected on her dual roles during the process: 'I felt very welcomed by the group. In the same way, being part of the management team means that there is always a barrier towards the community, perhaps self-imposed'. The challenge for organisations is to avoid the imposition of their commercial, social, political and technological interests in collaborative processes. MADA is one example of how a typical top-down quality certification process was transformed into an opportunity to listen, engage in dialogue and find common solutions for developing inclusive actions that the community perceived as valuable and meaningful. Creating a community that respects workshop participants' emotions enabled the facilitators to look at organisational decisions from a more bottom-up or organic perspective and follow the interests and expectations of its users.

\section{Conclusion}

We have discussed how a quality certification project carried out in a Master of Design programme at PUC was built with elements that can contribute to decolonising approaches. Hence, the project sought to decolonise such a process, which in 
educational contexts is usually top-down and authoritative. One of the challenges of the project was the interdisciplinary characteristics of the postgraduate programme, because it required greater flexibility to define the scope of the community and a level of precision that makes sense to all its members, regardless of the academic and practical background of each participant. In the case of MADA, interdisciplinarity was experienced by users when they were exposed to the following: 1) a multidisciplinary learning environment composed of actors, such as teachers, students and graduates from different disciplines; 2) integration of the systemic thinking of the strategic design and design thinking in designers and non-designers, respectively; 3 ) constant mediation to address the complexity in the interaction and decision-making of the various actors in the same challenge; and 4) the convergence of the different approaches in the same methodological design application.

From a participatory service design perspective, the process carried out for the creation of the community emphasised the experiences, emotions and opinions of all participants to deepen a respectful understanding of the broadest and deepest interdisciplinary context. The development of this project enabled navigation of a plurality of perspectives contributed to making positions more flexible and horizontal, hence fostering dialogue to identify common expectations and desires. The interdisciplinary challenge was faced through a guided participatory service design practice which emphasised the empathic listening to and by the community that was vital to decision-making that is underpinned by local knowledge made available through the use of well-selected methodology, dissemination of information and sensitive guidance throughout the project by the facilitator/service designers involved. Furthermore, the project was a good example of service design practices that enable more emancipatory, autonomous and democratic processes of knowledge co-creation by and with the students.

Emotions are an essential consideration in the building of community. The responsiveness to emotions is tightly interwoven into decision- and meaning-making, which may present more challenges, but also add more depth to service design in general and to decolonising approaches in particular. Decision-making based on emotions contributes to building a community. Considering community identities and characteristics through observation, listening and promoting an attitude conducive to dialogue can create awareness of community members' emotions. Dialogue is a practical way to listen to the voice of the community, making visible their expectations and desires, in this case through the inclusion of the participants of the MADA community who contributed to more democratic knowledge co-creation. Through the value placed on local knowledge that was brought forth through the voices of the community, the students were able to actively reflect on and contribute their stories, feelings, expressions and visions to the development of MADA and, in the process, foster inclusion, dialogue and visibility.

Participation is a challenge because it requires an emotional balance to identify the best decisions according to participants' interactions, environments and specific situations, and the project's purpose. More inclusive and decolonising approaches to service design are linked with the ability of service designers to carry out projects through participatory practice. Service designers can assume the role of coordinator, facilitator or member of the community. Considering all the various parts of a community that constitute a complex system of relations can prompt a reflection on the role of service designers as being only a small part of that system. Hence, they have 


\section{2}

to develop or strengthen adaptive skills connected with their emotional and behavioural responses, such as empathy and respect, to cope with the possible situations. Service designers need to question their roles in processes and be willing to step aside to enable learning for community members to express their needs and co-create possible solutions to those needs. Thus, emotions can mitigate the usual power structures in workshops, fostering egalitarian interaction and attitudes from participants and facilitators by bringing together their various experiences. The job of service designers from this perspective is to be facilitators of spaces in which the convergence of opinions promotes respect for differences, and to serve as actors who contribute with their experience to visualise possible paths.

Decolonising approaches to service design should be holistic, plural, inclusive and horizontal processes that are applied by continuously questioning and reflecting on the power that may result from an expert position as a facilitator/service designer. Thus, the skills for remaining sensitive need to be nurtured and developed to distinguish between plural emotions and behaviours. By stepping aside, service designers can provide spaces for creating community identity and even livelihoods. This will also afford opportunities for service designers to question their agency and reflect on how their solutions will impact the communities in which they work, as design is not a neutral practice but it is influenced by Western thought. Empathy and respect are basic approaches to developing decolonising service design practice, as facilitators need to address the complexities in interactions through dialogue. Flexible, participative and locally adapted methods, such as workshops, can encourage a fundamental inclusion of the expectations and desires of communities. Workshops, once approached in this fashion, are valuable spaces for drawing on and including a variety of forms for creating and making, including design, arts and craft methods. Such approaches avoid artificial divides that were theoretically and in practice set up amongst arts, crafts and design in Western knowledge systems.

This case study affords insights into a bottom-up evaluation process in a Chilean university. Although a decolonising approach was not adopted from the onset, upon reflection on the project, such approaches were revealed that can be further expanded and adopted into more rigorous processes in the future. This chapter contributes to a collection of case studies that can elaborate on an understanding of what aspects of decolonising approaches may be entailed, while contributing to the education of designers and service designers who are working with the aspirations and dreams of communities.

\section{References}

Aven, T., \& Zio, E. (2011). Some considerations on the treatment of uncertainties in risk assessment for practical decision making. Reliability Engineering \& System Safety, 96(1), 64-74.

Bhambra, G. K., Gebrial, D., \& Nişancıoğlu, K. (2018). Introduction: Decolonising the university? In G. K. Bhambra, D. Gebrial, \& K. Nişancioğlu (Eds.), Decolonising the university (pp. 1-15). Pluto Press. https://library.oapen.org/bitstream/handle/20.500.12657/25936/1004145. pdf? sequence $=1$

Bohm, D. (2013). On dialogue. Routledge.

Cabanac, M. (2002). What is emotion? Behavioural Processes, 60(2), 69-83.

Cantù, D., Corubolo, M., \& Simeone, G. A. (2012, February 8-10). Community centred design approach to developing service prototypes. Proceedings of the Service Design Conference (pp. 65-70). Helsinki. 
Desmet, P. (2002). Designing emotions. Delft University of Technology.

Ekman, P., \& Cordaro, D. (2011). What is meant by calling emotions basic. Emotion Review, 3(4), 364-370.

Frijda, N. H. (1988). The laws of emotion. American Psychologist, 43(5), 349-358. https://doi. org/10.1037/0003-066X.43.5.349

Frijda, N. H., \& Parrot, G. W. (2011). Basic emotions or ur-emotions? Emotion Review, 3(4), 406-415. https://doi.org/10.1177/1754073911410742

George, J. M., \& Dane, E. (2016). Affect, emotion, and decision making. Organizational Behavior and Human Decision Processes, 136, 47-55.

Ghose, R. (1989). Design, development, culture, and cultural legacies in Asia. Design Issues, 6(1), 31-48.

Hoffman, M., Lubell, M., \& Hillis, V. (2015). Network-smart extension could catalyze social learning. California Agriculture, 69(2), 113-122.

Hogan, C. (2007). Facilitating multicultural groups: A practical guide. Kogan Page.

Judice,A. (2014). Design for hope: Health information in Vila Rosário [Doctoral dissertation, Aalto University publication series: Doctoral dissertation 95/2014. School of Arts, Design and Architecture]. Aalto ARTS Books. https://aaltodoc.aalto.fi/handle/123456789/15242\#files-section

Khandwala, A. (2019). What does it mean to decolonize design: Dismantling design history 101. IGA Eye on Design, 7. https://eyeondesign.aiga.org/what-does-it-mean-to-decolonizedesign/

Kuure, E. (2017, November 29-30). Workshops as a catalyst for common good. Proceedings of the Art of Research VI Conference, Aalto University Publications. Espoo. http://artofresearch2017. aalto.fi/chapters/6_Essi_Kuure.pdf

Kuure, E., Miettinen, S., \& Alhonsuo, M. (2014, June 16-19). Change through service design: Service prototyping as a tool for transformation and learning. Proceedings of DRS 2014: Design's Big Debates (pp. 469-482). Umeå Institute of Design, Umeå University, Umeå, Sweden.

Lerner, J. S., Li, Y., Valdesolo, P., \& Kassam, K. S. (2015). Emotion and decision making. Annual Review of Psychology,66(1),799-823.https://doi.org/10.1146/annurev-psych-010213-115043

Lohaus-Reyes, M. (2019). Curricular decolonization from epistemologies of diversity. Transnational Curriculum Inquiry, 16(1), 74-80. https://ojs.library.ubc.ca/index.php/tci/index

Manzini, E. (2009). Service design in the age of networks. In S. Miettinen \& M. Koivisto (Eds.), Designing services with innovative methods. University of Art and Design Helsinki.

Mattelmäki, T., Vaajakallio, K., \& Koskinen, I. (2014). What happened to empathic design? Design Issues, 30(1), 67-77.

Meroni, A. (2008). Strategic design: Where are we now? Reflection around the foundations of a recent discipline. Strategic Design Research Journal, 1(1), 31-38.

Miettinen, S., du Preez, V., van Dugteren, J., Moalosi, R., Molokwane, S., \& Luojus, S. (2016). Service design with communities in Africa: The case of UFISA. International Academy of Technology, Education and Development.

Miettinen, S., Rontti, S. J., \& Jeminen, J. (2014). Co-prototyping emotional value. Proceedings of the 19th DMI International Design Management Research Conference: Design Management in an Era of Disruption: Bohemia (pp. 1228-1246). Design Management Institute, London.

Miettinen, S., \& Sarantou, M. (2019). Managing complexity and creating innovation through design. Routledge.

Miettinen, S., \& Valtonen, A. (2013). Service design with theory: Discussions on change, value and methods. Lapland University Press.

Mignolo, W. D. (2006). Citizenship, knowledge, and the limits of humanity. American Literary History, 18(2), 312-331.

Mikkonen, E. (2017). Bridges over the mountain ranges: Ethnography on the complexities of transition in women's social position in Nepalese rural communities [Doctoral dissertation, 


\section{Mariluz Soto Hormazábal et al.}

University of Lapland, Finland]. https://lauda.ulapland.fi/bitstream/handle/10024/62849/ Mikkonen_Enni_ActaE_221pdfA.pdf?isAllowed=y\&sequence $=1$

Mollenhauer, K., Moraga, E., \& Bernasconi, R. (2020). Modelo instrumental para proyectos complejos. Poliedro Propuesta de Valor Académico [Instrumental model for complex projects: Polyhedron of the academic value proposition]. Bitácora Urbano Territorial, 30(2), 127-140. https://doi.org/10.15446/bitacora.v30n2.81661

Mollenhauer, K., \& Soto, M. (2019). From citizens to community: The complexity in the context and the transformation and the challenges of modernising Chilean services. In S. Miettinen \& M. Sarantou (Eds.), Managing complexity and creating innovation through design. Routledge.

Moritz, S. (2005). Service design: Practical access to an evolving field. Köln International School of Design. University of Applied Sciences, Cologne. http://stefan-moritz.com/_files/Practical\%20 Access $\% 20$ to $\% 20$ Service $\% 20$

Motta, S., Gomez, N. L. B., Fuentes, K. V., \& Dixon, E. S. (2020). Student movements in Latin America: Decolonizing and feminizing education and life. Oxford Research Encyclopedias. https://oxfordre.com/politics/view/10.1093/acrefore/9780190228637.001.0001/ acrefore-9780190228637-e-1721

Norman, D. (2004). Emotional design. Basic Books.

Plutchik, R. (2001). The nature of emotions: Human emotions have deep evolutionary roots, a fact that may explain their complexity and provide tools for clinical practice. American Scientist, 89(4), 344-350.

Prahalad, C. K., \& Ramaswamy, V. (2004). The future of competition: Co-creating unique value with customers. Harvard Business School Press.

Sanders, E. B.-N., \& Stappers, P. J. (2008). Co-creation and the new landscapes of design CoDesign. International Journal of CoCreation in Design and the Arts, 4(1), 5-18.

Schön, D. A. (1984). The reflective practitioner: How professionals think in action (Vol. 5126). Basic Books.

Schultz, T., Abdulla, D., Ansari, A., Canli, E., Keshavarz, M., Kiem, M., Martins, L. Prado de O., \& Vieira de Oliveira, P. J. S. (2018). What is at stake with decolonizing design? A roundtable. Design and Culture, 10(1), 81-101.

Simons, H. (2009). Case study research in practice. SAGE Publications.

Smith, L. T. (1999). Decolonizing methodologies: Research and indigenous peoples. Zed Books.

Soto, M. (2018, May 18-19). Emotional variables of interactions inside of community. Proceedings of Sider '18 14th Student Interaction Design Research Conference (pp. 69-72). Helsinki.

Soto, M., Beaulé, C., Alhonsuo, M., \& Miettienen, S. (2020, August 26-28). Emotions: The invisible aspect of co-creation workshops. The Sixth International Conference on Design Creativity ICDC Conference 2020, Oulu, Finland. http://icdc2020.org/files/proceedingsicdc2020.pdf

Soto,M.,\&Kaplún,M.(2019,May27-June 01).The emotions thatemergein the collectivecreation in a marginal context: Experience in a Chilean prison. Cumulus Conference Proceedings Series (pp. 743-75). Rovaniemi. www.cumulusrovaniemi2019.org/loader.aspx? $\mathrm{id}=4977 \mathrm{f} 4 \mathrm{de}-$ 45ad-4a5f-b3d3-ec7936db30e0

Soto, M., Mikkonen, E., \& Miettinen, S. (2020). Emotions and the service designer: A relationship uncovered. Diseña, 17, 84-105. https://doi.org/10.7764/disena.17.84-105

Thaler, R., \& Sunstein, C. (2009). Nudge. Penguin Books.

Tolosa, M. (2008). A twist in communication: The power of the oasis. https://ssrn.com/ abstract $=1310227$

Tolosa, M. (2009). To communicate is to create communities. Dixit, 10, 30-35. https://revistas. ucu.edu.uy/index.php/revistadixit/article/view/273

Tolosa, M. (2013). Communities and social network, the collapse of pyramids. Publisher Papyrbit. 
Tunstall, E. (2013). Decolonizing design innovation: Design anthropology, critical anthropology, and indigenous knowledge. In W. Gunn, T. Otto, \& R. C. Smith (Eds.), Design anthropology: Theory and practice (pp. 232-250). Bloomsbury Academic. http://doi.org/10.5040/9781474 214698.ch-013

Walker, P. (2000). Native approaches to decolonising education in institutions of higher learning. The Australian Journal of Indigenous Education, 28(2), 28-34.

Wilson, C. (2001). Decolonizing methodologies: Research and indigenous people. Social Policy Journal of New Zealand, 214-218. 